\title{
Contested Sustainabilities: Assessing narratives of environmental change in southeastern Turkey.
}

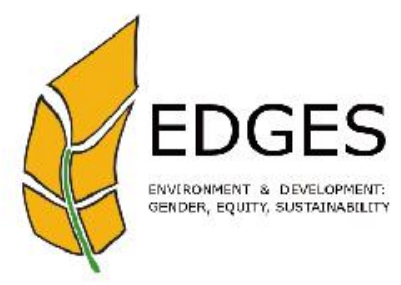

\section{LEILA M. HARRIS}

Corresponding Author: Iharris@ires.ubc.ca

2009

Final version: Harris, L. (2009) Contested Sustainabilities: Assessing narratives of environmental change in southeastern Turkey. Local Environment 14 (8): 699-720. DOI:

$10.1080 / 13549830903096452$

Citations of this work should use the final version as noted above 


\section{Table of Contents}

SUMMARY

I. Introduction: Partialities and Spatialities of Knowledge

II. Assessing sustainability, Diverse Knowledges, and Narrative/Discursive Approaches to Environmental Change.

Conditions of Possibility for Assessing Sustainability ........................................... 5

Engaging multiple knowledges: attention to the 'local' ............................................ 6

Narrative and Discursive Approaches in Environmental Studies ............................ 7

III Irrigated Agro-Ecologies: Narrations of Change in Southeastern Turkey ................... 9

Assessing Sustainabilities: Techno-Scientific Knowledges and Adaptive Capacities 10 (In)Appropriate Knowledge, Farmer Training, and Irrigation Mishaps....................... 12

Peasant Scientists: Finite Possibilities and Partial Mobilizations ............................. 15

IV Divergences and Convergences: Learning from Different Natures .......................... 18

V. Conclusion: Environmental Calcabilities/ Assessing Sustainabilities ........................ 22

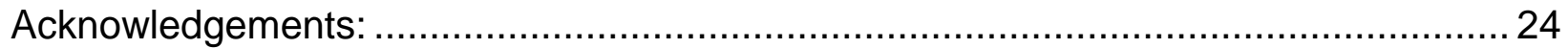

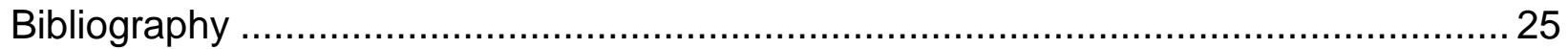




\section{SUMMARY}

This article contends that there is a need to more fully assess convergences and divergences between local environmental narratives in studies of environmental change and evaluations of sustainability. While much work has established the importance of being attentive to local knowledges the possibility of evaluating points of overlap and dissonance between diverse narratives of change offers a particularly fruitful path for future work. Drawing on survey data and interviews related to irrigation-related changes in southeastern Turkey, narratives of environmental change offered by different actors are analyzed to highlight key points of overlap and tension. Specifically, there is general agreement that degradation is occurring, even as actors disagree on the causal explanations for these changes. More revealing, narratives also share a tendency to validate technoscientific approaches and continued state intervention thus revealing crucial insights related to future agroecological possibilities in this region. Apart from offering empirical insights from a context in the Middle East where social science evaluations of environmental change and sustainability remain relatively thin, the analysis also speaks to broader theoretical and methodological concerns at the intersection of debates related to local knowledges, narrative and discursive approaches to environment, and sustainability.

Keywords: sustainability, degradation, experiences of development, narrative, environmental change, local knowledges, irrigation, Turkey 


\section{INTRODUCTION: PARTIALITIES AND SPATIALITIES OF KNOWLEDGE}

'Thus, in the second half of the nineteenth century a new discourse of hydrology and hydraulic engineering emerged which translated 'nature' into mathematical formulae. In these there would be no place for 'local' knowledge and the hydraulics of irrigation channels and the mechanics of dam construction could be made the same the world over'

(Derek Gregory, 2001: 97)

We followed several irrigation engineers to the village of Yaytaş near Diyarbakir in southeastern Turkey. As part of the larger GAP project (Southeastern Anatolia Project), a nearby dam would be completed the following year. Soon thereafter pumped irrigation water would begin to flow to the farmers of the village through a network of irrigation canalets. The purpose of the trip was to initiate a set of discussions between Turkish state irrigation engineers and local farmers about what these changes would mean. As we traversed the semi-arid landscape, the engineers explained that irrigation would not be successful unless the farmers themselves feel a sense of ownership for the system. Indeed, the engineers noted that this was the only way farmers would take on responsibility for canal maintenance or have incentives to grow appropriate crops. The engineers continued to stress these issues, making it clear that the future of local livelihoods, agroecological change, and the long-term sustainability of the project lay in the hands of the farmers themselves.

As the meeting with village men proceeded in the school house, the engineer who conducted the meeting repeatedly stressed the importance of local knowledge and local input to the success of the project,

'this land is yours. We want to work together with you in the way that you want us to work. We want this land to stay good for your children as well...We are not the owners of this land, we are strangers. That's why we don't know what you grow, what the problems of the soil are. We are agricultural engineers. We cannot know the best version of everything, but we can claim to bring better results when we work together. The water is yours, the land is yours, and we want the benefits of irrigation to be yours as well. We want you to benefit and we want the benefit to be permanent.'

With these words, and repeated displacement of himself as an expert-- 'hoja değilim $\mathrm{ki}$, '- I am not a teacher-this irrigation engineer echoed themes that have long been discussed in the development literature-that scientific knowledge of biophysical systems is not sufficient to achieve sustainability and that it is necessary to engage with and understand local knowledges and motivations to achieve project success. Indeed, 
the literature is replete with studies that argue that it is likely to be local peoples' understandings of, and interpretations of, biophysical processes that hold the greatest import for environmental and developmental change over the long-term. Conditions that would be manifest in the village in five, ten, or fifteen years would be importantly conditioned by local understandings of irrigation, of crop needs and requirements, and of adaptive and mitigation strategies to curb salinization, soil loss, or other associated degradation.

Even as the planners acknowledged the importance of local knowledge, there was obvious irony that unfolded during our meetings given that the state water agency (DSi, Devlet Su İşleri) had failed to ground-truth plans for the irrigation network, locating many canalets in locations that local people considered to be far from arable lands. The former muhtar (village head) offered a protest along these lines during our meeting, 'the engineer did the canalets on the map. He did not come here to see. In some places (where they located the canalets), you cannot find even a gram of soil, even when you explode an atom bomb. And in some places, there is soil for agriculture, but there is no canalet around. On paper, Hacı Ömer has 100 decares of land, but in reality, you only find soil in 5 decars of that land. The rest is rocks and stones.' The irony is even more acute when you consider the name of the village, Yaytaș, which is roughly translatable as 'spreadout stones." This situation was one that could serve as a textbook example of why many have challenged the appropriateness of abstracted, technical, or bureaucratic knowledges (e.g. Scott, 1998), or have called for greater inclusion of local knowledges in resource management and development planning (see Berkes et. al, 1998, Ostrom, 1990, Peet and Watts, 1993).

Even as scholars and planners have learned a great deal about the importance of local knowledges, and even as we have significantly complicated our understanding of local knowledges as hybrid, and not wholly separable from 'expert', 'state' or 'scientific' knowledge (see Robbins, 2000, Agrawal, 1995, Nygren, 1999), this article argues that there remains room to further enrich treatment of these issues through greater attention to narrative, and in particular, the complex mapping of diverse narratives to analyze key points of divergence and convergence among them. Focus on narrative calls attention to stories that are told about environmental issues, allowing analysis of ways that changes are attributed as positive or negative, or of the ways that environmental conditions are often discussed in relation to other issues-highlighting the embeddedness of environmental issues in broader power relations, histories and contextual issues (see Fisher, 2003). ${ }^{2}$ By analysing narratives from diverse actors, we can also think about issues of attribution and causality that are central to the plot and storyline of stories that circulate. Who is positioned as causing observed changes, who is to blame for the change, and by extension, who or what might be called for to overcome or respond to particular environmental conditions? Do particular storylines enrol well-known plots that may hold meaning in a particular context, or replicate

\footnotetext{
${ }^{1} \underline{\text { Yay }}$ means spread, and tas means stones.

2 There is strong overlap between the way that I am drawing on narrative, and others have discussed environmental imaginaries (Peet and Watts, 1996). For instance, Cowell and Thomas (2002) similarly engage a discussion of environmental imaginaries to consider meanings and signification related to environment that stem from material and social practices in specific contexts, including how these imaginaries are mobilized in environmental politics.
} 
familiar notions of who the heroes or victims might be? The interest in narrative is distinct from to validate the veracity of one claim over another (as with many examples that attempt to demonstrate the suitability of indigenous knowledges as preferential to abstracted state knowledges). The focus on narrative also helps to avoid common pitfalls of treating knowledges as static, or as closely linked to certain positionalities (e.g. indigeneity, gender, ethnicity, location). Instead, the primary interest is to draw insights from the complex mapping of stories that are told about environments, especially to evaluate resonances and tensions between them and to connect these storylines to broader social, historical, and contextual issues. Whether or not these stories are 'true' are accurate, they are nevertheless critical for conditioning local responses and mitigation strategies, future environmental conditions, or potential for 'sustainability.' Indeed, I argue that meanings and associations of changes assigned by those who transform, negotiate, and interpret environments on a daily basis are as crucial for agro-ecological sustainability, if not more so, than understanding the contours of changing agro-ecological conditions themselves (see also Visser et al, 2003, Van Dissel and de Graaff, 1998, Adams and Watson, 2003, Lee and Zhang, 2004).

The argument proceeds as follows. First, I provide a brief discussion related to sustainability debates, local knowledges, narrative and discursive approaches to environment to draw out key themes in work of this type to date. I then turn to a detailed discussion of diverse, and contested narratives of (un)sustainability related to irrigation related changes in southeastern Turkey. How are changes narrated by diverse agents experiencing and negotiating ongoing agro-ecological and irrigation related changes? What are key points of divergence and convergence between these assessments? In the conclusion, I revisit what detailed analyses of narratives and meanings of this type offer to studies of environmental change and to sustainability debates.

\section{ASSESSING SUSTAINABILITY, DIVERSE KNOWLEDGES, AND NARRATIVE/DISCURSIVE APPROACHES TO ENVIRONMENTAL CHANGE}

\section{Conditions of Possibility for Assessing Sustainability}

To date, most works on sustainability have followed several primary lines of inquiry. The first, and most prevalent, is to ascertain whether or not a particular system or process is or is not sustainable. For instance, work seeks to evaluate soil and water productivities with goals of promoting practices that are 'more sustainable' by avoiding degradation or regenerate needed soil nutrients. Many such analyses inhere normative

\footnotetext{
${ }^{3}$ It may appear curious to insist on the value of narrative studies at a moment when many scholars have been emphasizing the need to bring 'materiality' back in to political ecology and nature-society discussions (e.g. Bakker and Bridge, 2006). I agree with these scholars that engagement with biophysical properties of the natural world has much to offer. However, my project here more narrowly aims to enrich cultural, social, and political-economic approaches of resources and natures.
} 
judgments that privilege certain definitions, realms, or scales of sustainability over others (see Sneddon et al., 2002). Another key set of works pose critical questions about sustainability discourses and practices. Some argue, for instance, that sustainability lacks coherency as a concept (Lélé, 1991), while others emphasize that sustainability discourses tend to mask important inequalities, at times perpetuating overuse of resources (e.g. Escobar, 1995; Shiva, 1993). While clearly problematic, the widespread acceptance the term enjoys among policy communities and development practitioners, as well as its utility in fostering recognition of human-environment linkages provide sufficient reason for continued engagement. An emergent third track of sustainability studies can also be traced, seeking to rethink sustainability tools and concepts. For instance, Sneddon (2000) offers redefinition of key questions along the lines of 'what is being sustained, at what scale, by and for whom, and using what institutional mechanisms?' (p. 525).

Consistent with this third track, the approach taken here seeks to shift sustainability assessments in a way that is attentive to partial and situated knowledges (Haraway, 1991, see also Kloppenburg, 1991), and discursive and narrative approaches to environment (e.g. Adger et al, 2001, Fisher, 2003). Rather than asking whether a system or practice is or is not sustainable, or 'what is being sustained, for whom, at what scale, and by what mechanisms,' this study seeks to evaluate how sustainability, or threats to sustainability, are variously expressed, and attributed. Doing so opens possibilities for other novel evaluations, such as discussions of how and why diverse discourses of environmental change and degradation circulating in the Southeastern Anatolia region converge, and notably differ. In the sections that follow, I revisit questions of what analysis of divergent and convergent narratives of (un)sustainabilities offers for discussions of environmental change more generally.

\section{Engaging multiple knowledges: attention to the 'local'}

As the introductory story provided at the beginning of this article suggests, there has been increasing recognition of the necessity to engage with local knowledges in developmental and environmental interventions. Scott (1998) provides an often-cited example of work that highlights the failures of abstracted universalised knowledges (techne) when confronted with 'on the ground realities.' To overcome such challenges, Scott insists on the value of metis, or local knowledges that are attuned to context and adapted to changing conditions over time. In the realm of resource management, many recent ongoing trends (e.g. 'Irrigation Management Transfer' or 'Community Based Conservation') seek to enrol local people, and their knowledges, directly in resource governance. The common refrain is simple: any intervention that is inattentive to historical and geographical specificities, local conditions, and local knowledges, will likely fail.

Many have explored the possibilities and consequences for integrating local knowledges in development planning or conservation efforts (e.g. Briggs and Sharp, 
2004, Goldman, 2001), or difficulties and limitations of incorporating indigenous knowledges into certain knowledge frameworks, such as geographic information systems or participatory mapping (Robbins, 2003, Hogdson and Schroeder, 2002, Johnson et. al, 2006). Others have sought to clarify what is meant by 'indigenous', or 'local' knowledges, questioning relationships between knowledge and fixity in 'place' (Brosius, 2006), or calling attention to 'hybridities' of local knowledges not readily distinguishable from 'scientific', 'state' or 'expert' understandings (for instance, see Murdoch and Clark, 1994, Robbins, 2000, Nygren, 1999, or Agrawal, 1995, or Gupta 1998 for discussion). Among other interesting themes for future analysis that have been established by this literature: how can we understand 'local' knowledges as situated in broader contexts and scales, including their constitution in relation to emergent global arenas (such as global conservation agendas or indigenous rights movements, see Brosius, 2006)? Further, how do certain local knowledges become validated by NGOs, states or other actors, what do such alliances mean for furthering certain truth claims (Robbins, 2000), or even how might conflicting environmental knowledges adversely affect management possibilities for vulnerable resources (Birkenholtz, 2008)?

\section{Narrative and Discursive Approaches in Environmental Studies}

Discursive and narrative approaches to understanding environmental conditions and changes have also gained currency in academic and policy circles. Contributions by Hajer (1995), Roe (1999), Adger et al (2001), or Fisher (2003) are all notable examples of works along these lines. There is a great deal of interest in these discussions, although as noted below, there are several limitations of this work that stem from tendencies to privilege national or global scales, to analyze abstracted, acontextual knowledges, and also common tendencies to typologize and cast 'ideal type narratives' for purposes of analysis.

Among discursive approaches, Hajer argues that the is a need to evaluate images and discourses that circulate around stories of 'ecological crisis.' His particular example draws on acid raid debates in Great Britain and the Netherlands to evaluate the influence of 'stories we tell about environmental change.' For Hajer, discourse is crucial as the "ensemble of ideas, concepts, and categorizations that are produced, reproduced, and transformed to give meaning to physical and social relations (73)." Fisher also argues for a discursive approach, focusing on the ways that policy actions are "shaped and controlled by the discourses that supply it with meaning" ( $\mathrm{p} 23)$. A discursive analysis includes attention to regularities of expression, analysis of actors reproducing and transforming discourses, as well as the social impacts or policy outcomes of discourses (Adger et. al, 2001). On the whole, approaches of this type have drawn attention to the social practices and power relations in which interpretations of environmental phenomena are embedded, and the consequences this may have.

Closely linked to discursive approaches, attention to narrative considers the particular language and storylines that different people draw on in making claims or identifying their positions. Narratives often serve to structure ways of apprehending the world through plot, metaphor, or description of characters. Indeed, particular narratives of environmental conditions or changes are often structured in ways that enable the reader 
or listener to come to certain conclusions about the world. Narrative analysis, then is concerned with analyzing stories of environmental conditions, seeking to answer questions such as 'who benefits' from particular framings of the issues, or what elements are occluded by particular framings? Additionally, focus on narrative allows the analyst to attend to the policy prescriptions, interventions, or other actions that are implicitly authorized by particular narratives. Given the story being told, what actions are being promoted or implicitly authorized to address the situation?

There remains somewhat of a disconnect between this rich and growing literature, often focused on national or global scale discourses and policy debates (as with the Hajer example above) or even abstracted 'placeless' narratives (e.g. tragedy of the commons), and the interest in 'local' knowledges highlighted above. As argued by Adger et al (2001), discourses of major 'global environmental issues' (deforestation, desertification, biodiversity, and climate change) are largely illegible at the local scale. Observations of this type pose a challenge to better understand scalar linkages between discourses, to better understand why and how certain narratives hold meaning for certain actors in particular times and places, and to better understand ways that narratives circulate, and are transformed by various interactions and engagements (see also Paulson and Gezon, 2005, Brosius 2006). Specifically: in what ways do local actors reflect broader narratives in ways that can tell us something about power dynamics? Why might particular stories take hold and become invested with meaning in particular times and places, and why might key elements of narratives be shared among diverse actors (Brosius, 2006)? While there are some works that consider local narratives of environmental conditions and changes, most commonly these efforts typologize local knowledges, either based on 'ideal types' (e.g. Soliva, 1997), ${ }^{4}$ or positionality (e.g. gender, caste, or ethnicity, e.g. Davis, 2005). Further, there are common tendencies to assess the validity of local knowledges by testing them against some understanding of scientific 'truth' (see Krogh, 1997 for example, or Murdoch and Clark 1994 for discussion), or to engage local knowledges with the goal of challenging broader scale narratives (e.g. challenging 'crisis' narratives common to colonial or statist development projects, see Fairhead and Leach, 1995, or Davis, 2005). While these contributions are useful, my aim here is slightly different. Instead, my goal is to highlight what can be gained by maintaining attention to the complexity and diversity of narratives, and also to consider what highlighting resonances and dissonances between diverse narratives might reveal for broader contextual issues, historical considerations, or other relations in which these narrations are necessarily embedded. As such, the approach here shares elements with earlier work by Tsing (2005) that attends to the 'friction' between stories told by different environmental activists in the Indonesian context, as well as arguments by Nightingale (2009a, 2009b) about the value of work that seeks to analyze points of tension between different knowledges as particularly revealing to understand socio-

\footnotetext{
${ }^{4}$ Specifically, in Soliva's case, local narratives are coded as one of several ideal types for analytical purposes. The author maintains that 'ideal types' are useful, however, he concludes by noting that when research subjects are presented with all four ideal type narratives used in the analysis, they were likely to agree with all of them. He thus concludes by noting that knowledges are most likely to be hybridized across the 'ideal types.' Here, I am suggesting that rather than pinning analysis on 'ideal types' (e.g. ecological modernization, or tragedy of the commons), much can be learned by being attentive to the complexity and diversity of environmental narratives, including overlap and tension between them.
} 
politics of knowledge claims, or to understand how diverse knowledges are mobilized by different groups. The theoretical and empirical discussion that follows is meant to further explore the potential value of an approach that maps convergences and diverges between diverse narratives of change. I do so in a way that moves beyond appeals to 'add local knowledges', or assessments of national or abstracted discussions of environmental discourses to identify key themes, shared storylines and points of dissonance. I argue that doing so is crucial to assessing future environmental conditions and possibilities.

\section{IRRIGATED AGRO-ECOLOGIES: NARRATIONS OF CHANGE IN SOUTHEASTERN TURKEY}

The narratives from southeastern Turkey presented here have been collected through document analysis, open-ended interviews with state agents and rural residents, and a village survey in newly irrigated areas of the Harran plain conducted in 2001, with follow-up work conducted in 2004, 2005 and 2007. By exploring the convergences and divergences of understandings of, and possible responses to, changes underway as part of the large-scale Southeastern Anatolia development project (GAP), the analysis situates contested and partial understandings within wider socio-political relations, cultural associations, and operations of power. Although I introduce diverse knowledges in successive layers, highlighting the overlap and divergences between them in the following sections will bring to focus the hybridization of knowledges (cf. Gupta, 1998), deflecting any reading of these knowledges as isolatable and distinct.

Taken together, analysis of narratives of agro-ecological change in this context reveals that various actors concur that environmental degradation is occurring with continued irrigation implementation. Indeed, there appears to be widespread agreement among state agents and farmers that soil erosion, salinization, and increased numbers of pests associated with cotton, among other factors, threaten long-term productivities of soil and irrigated agriculture. However, as the examples below illustrate, there are divergent views and emphases as to what the 'causes' of these problems may be. For instance, among state agents and large landowners, environmental degradation may be attributed to illiteracy and lack of training among farmers. For other farmers, environmental problems may more often be attributed to the partial or inefficient mobilization of available technologies, for instance, with incomplete land levelling or drainage installation by state agencies. Thus, even with elements of storylines that are shared (degradation), the attribution of those stories, or the meanings attached to those stories differ (Hajer, 1995, see also Van Dissel and de Graaff 1998). More critically, other important points of overlap between narratives of change also emerge through the analysis. For instance, a key finding is that while diverse agents observe degradation occurring, and call attention to diverse 'unsustainabilities' they generally share a faith that sustainability of irrigated agriculture in this region remains possible. This 
convergence is particularly revealing, and offers key puzzles that can only be understood through consideration of cultural politics and contextual issues specific to the Turkish context, and to the southeast region.

\section{Assessing Sustainabilities: Techno-Scientific Knowledges and}

\section{Adaptive Capacities}

Several thousand years after salinization led to the abandonment of irrigated agriculture among the early settlements of upper Mesopotamia (Postel, 1999), irrigation is emerging anew. With a host of technologies now available, and careful monitoring of soil and water conditions, planners and scientists expect that a similar fate for contemporary irrigation efforts in upper Mesopotamia can be avoided. Irrigation is a key component of the larger GAP project, referred to by the Turkish planners as an "integrated regional sustainable development program" (e.g. Ünver, 1997a, 1997b). Guarding such optimism, major issues of concern have captured the attention of the international scientific community. Indeed, preliminary scientific evidence suggests that salinization, soil erosion, desertification, agricultural pests and other issues have already become evident in the first decade of irrigation delivery. ${ }^{5}$ Many of these trends have been observed in the pilot irrigation area of the Harran plain, representing the first ten per cent of the $1.7 \mathrm{M}$ hectares of the agricultural lands that will eventually be irrigated with continued diversion of waters from the Tigris and Euphrates rivers as part of GAP development (see Map 1, below).

\footnotetext{
${ }^{5}$ Some of these problems also were in evidence prior to widespread canalet irrigation, as some irrigation was already
} practiced in the plain using pumped groundwater. 


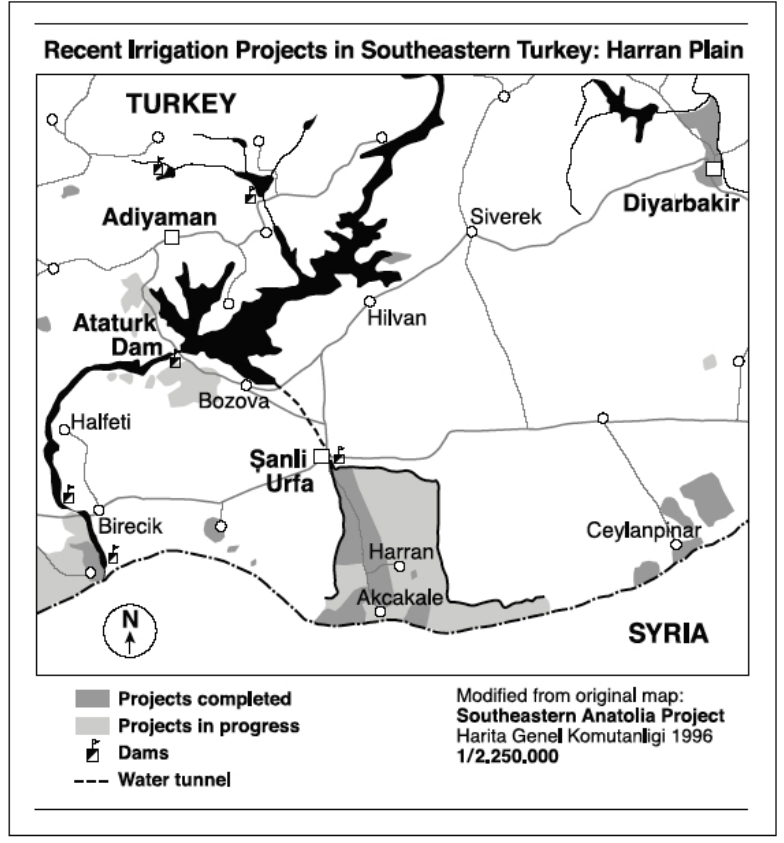

Map 1: Map of delivery of irrigation waters from Atatürk reservoir to the pilot irrigation in the Harran Plain, Southeastern Turkey.

For purposes of brevity, I provide only a few examples of research on changing conditions in the region to capture some of the ways that scientists and planners cast the threats to sustainability with ongoing irrigation implementation. Among other issues, in the first decade since irrigation implementation, it is estimated that salinization has already forced retirement of as much of fifteen per cent of agricultural lands in the plain, most notably in the southern reaches (Çullu, 2002). ${ }^{6}$ Exacerbating such trends, the cropping pattern is now estimated to be ninety per cent cotton, leading to difficulties associated with near mono-cropping, and also those specific to cotton as an inputintensive crop. Further still, the topography of the Harran plain has led to the creation of pools of stagnant water in many villages during the irrigation season (referred to as göl or lakes) with water seeping into homes, contributing to increased risk of malaria and other water-borne diseases. Understanding these issues, among others, ${ }^{7}$ is clearly critical for any attempt to evaluate future irrigation potential, associated health risks, livelihood securities, or other concerns commonly brought to light with evaluations of 'sustainability.'

It is notable however, that even with recognition of these issues, many planning documents and scientific assessments maintain a spirit of optimism with respect to the

\footnotetext{
${ }^{6}$ Using satellite imagery, Çullu estimates that the salinized area doubled in the first five years since surface irrigation was introduced to the plain.

${ }^{7}$ A longer list would include pollution risk of underground drinking water reserves, dietary changes, and concerns related to pesticide exposure among residents.
} 
potential for sustainability of irrigation in the region. In an evaluation of water use using remotedly sensed data Ozdoğan writes of the need to decrease rates of evaporation in future projects, "incorporating this decrease in overall planning of the irrigation projects currently under construction should lead to improved management, by extension, sustainability of water resources in the region. $(2006,467) . "$ This type of analysis recognizes vulnerabilities of the region related to histories of irrigation, soil conditions, topography, and even climate change, yet remains optimistic about the potential of engaging science and technology to improve outcomes and avoid ongoing degradation. University economist Adaman and colleague Özertan similarly provide a comprehensive treatment of threats to sustainability in irrigated areas of the GAP region from a social and economic perspective, pointing to difficulties associated with virtual monocropping of cotton, the lack of price signals to discourage overuse of irrigation water, and the inadequacy of furrow irrigation techniques among other factors. They goes on to suggest that with proper education of farmers, water pricing, incentives for crop diversification, the establishment of democratic water user associations, and modernization of irrigation techniques, many of these issues can be countered. While these types of assessments offered by independent scientists are less rosy than the pictures painted by GAP planners and government agents (see Ünver, 1997a, 1997b for prime examples), they still share an identifiable story line: better understanding, and science, can minimize threats to sustainability, and improve success of such projects over the long-term. Consequences of this shared storyline are to validate several related efforts: to observe, monitor and assess ongoing changes, to implement improved technology, and to teach or incentivize farmers to conduct appropriate farming to achieve sustainability.

\section{(In)Appropriate Knowledge, Farmer Training, and Irrigation Mishaps}

While sharing similar threads, somewhat different narratives of these changes circulate among actors living and working in the Southeastern Anatolian region. In an interview with sociologists at the offices of the regional GAP administration, one state agent explained ongoing difficulties related to irrigation adoption in the plain: ${ }^{8}$

'The people there used to be nomads, and then they earned a living as seasonal workers, picking cotton in Çukurova. No pre-study has been carried out about the people of Harran and how they will adapt to living with water. Before they didn't even have drinking water, now they have (irrigation) water and they can grow their own cotton. However, they are not prepared to live with water, and to earn big money.'

\footnotetext{
${ }^{8}$ Although I indicate statements as direct quotations, most often interviews with farmers were not recorded. Quotations were noted in field notebooks or were transcribed immediately following interviews. Interviews with state agents, by contrast, were most often recorded.
} 
In this portrayal, residents of the Harran plain are portrayed as facing difficulties with irrigation, unable to adapt to new conditions. In the same meeting, it was noted 'zor değisiyorlar, açık değil' [(local people) don't change easily, it is not clear how this will proceed]. Another said 'they don't want to change. One reason might be that they have doubts towards the state, since the state never brought them any service prior to the water development projects.' In another conversation, a state engineer summed up the obstacles related to crop diversification this way, 'people know how to grow cotton, they are not eager to learn any new crop and this shows how closed the society is to change' (S8). In all such statements, emphasis is given to the idea that farmers are resistant or unable to change, even as recognition is given that this resistance might stem from scepticism towards the state. In narratives of this type, threats to sustainability are attributed to the people, or cultures of the region. Following such logic, if sustainability is not achieved it can be readily attributed to obstinacy or ignorance of the local farmers. Such narratives of change (and inability of farmers themselves to change) are necessarily read through long histories of inequality between the Turkish state and Kurdish and Arabic speaking populations in the southeast region. Thus, the way that these issues are narrated is as much about cultural politics as they are about environmental conditions or irrigation technologies themselves (see Harris, 2002 for discussion of the importance of the Kurdish question to evaluations of water related changes in this context). Narratives along these lines demonstrate consistencies with 'expert' and 'state' narratives that have been evaluated in other contexts, echoing themes that have long been emphasized in the political ecology literature (e.g. as with the example of herders being blamed for degradation in Morocco, Davis, 2005, or similar discussions from Niger, Turner 1999).

Another narrative of degradation that is fairly common relates environmental problems to high percentages of sharecropping among farmers, directly related to high rates of landlessness. State agents, technicians, and landowners explain that because sharecroppers do not own the land, they have no interest in maintaining long-term soil productivity, or in learning appropriate irrigation techniques. As one state agent explained, referring to sharecroppers, 'they don't have the initiative to implement a new program for the land.' As part of such explanations, the fact that sharecroppers often farm different land parcels from year to year is invoked to demonstrate that they have little investment and interest in protecting the soil and mitigating against further damage.

Related to these discourses, outreach efforts of state extension agents currently focus on 'teaching' local farmers, for instance by telling them to us less water, or by investing in demonstration farms to show farmers the value of planting tomatoes, orchards, or other crops. These portrayals and policy directives often cast farmers inter alia as practicing inappropriate agriculture, having insufficient knowledge, or suffering from illiteracy or other condition that might impede sustainable agricultural potential. In a focus group of irrigation engineers employed at Irrigation Unions (Sulama Birliği) similar ideas were reinforced. The engineers note, for instance, that not knowing any better, farmers add water in excess of what is needed to grow the crops, leading to 
degradation. ${ }^{9}$ In other narratives, the over-reliance on cotton was directly connected to high rates of illiteracy among farmers.

Concurrent with these explanations, discourses also circulate that emphasize the knowhow and good intentions of the state in attempting to promote sustainability. For instance, one irrigation extension agent said:

'We tell people the aim of the project. Our aim is to invest in people, to benefit from natural and human resources in the best way. However, because of wrong irrigation practices, the most fertile layers of soil are degraded and carried to Syria. 400 years are required for the formation of a one-centimetre thick layer of fertile soil. What we are trying to do is implement sustainable use of water resources.'

With this statement, the planner asserts his own scientific understanding of soil fertility, suggesting that state agents have the knowledge to make 'sustainable use of water resources' possible. Here it is of interest not only that farmers lack the knowledge of appropriate farming or familiarity with science, but that the state in general, and irrigation engineers in particular, would be able to achieve sustainability were it not for this deficit. Through a litany of similar statements encoded in state planning documents and conveyed in interviews, the kernel that is again common to these narratives is that sustainability is possible, and that scientific assessment and techniques could allow for sustainable irrigation in the region. Apart from lack of agricultural knowledge, landlessness and illiteracy are also discursively linked to unsustainabilities, connecting these environmental narratives to long histories and policies related to socio-cultural attributes of this 'backward' region dominated by Kurdish and Arabic speakers (see also Author, 2008). In some cases, 'unsustainabilities' are linked to lack of resources and investment on the part of the state [e.g. some narratives focus on the need for more training and agricultural extension, e.g. Akbaba, 2001 and Şelli and Koral, 2000, or arguments made by Adaman et al, 2007]. ${ }^{10}$

Farmers too echo such narratives, for instance highlighting their own ignorance, or identifying the need for more farmer training, illustrating that these narratives are not exclusive to state agents and scientists. ${ }^{11}$ This type of hybridised knowledge is of

\footnotetext{
9 This is often noted especially given the relatively inexpensive access to irrigation water (approximately four dollars US per decare for an entire season for cotton, regardless of amount of water used). In one study of this issue conducted by agricultural economists, it was estimated that farmers apply twelve per cent more than the actual amount of water needed for cotton (Şelli and Koral, 2000).

10 The idea that more farmer training is needed is also the impetus behind the agricultural extension effort in the GAP region--MOM, Maintenance Operation and Management of Irrigation Systems — staffed by irrigation engineers and designed to help with adoption of effective irrigation techniques.

${ }^{11}$ In our survey of rural households in the Harran plain nearly eighty-three per cent of respondents noted a 'problem with insufficient agricultural training and education' in their village. The vast majority of respondents, seventy nine per cent, also noted that they had never attended an irrigated-related course or read informational materials. The 2001 survey of 124 rural households in the Harran plain was conducted cooperatively with Professor Karahan Kara of Harran University. Survey respondents included non-farmers, such as school teachers. As such, participation of these
} 
particular interest, both to illustrate that farmer and state knowledges are not discrete categories (see also Gupta, 1998, Robbins, 2000) as well as to consider how and why similarities circulate among narratives of change offered by diverse agents.

Other farmers also expressly reject such framings, often demonstrating awareness that their knowledge of farming and irrigation is actively questioned, and interjecting their voices into debates about how appropriate or sustainable farming might be practiced. Consider the statement made by an Arabic speaking farmer in the southern reaches of the Harran plain,

'many agricultural engineers and others come to talk with us about water use, fertilizer, etc... but every farmer is as knowledgeable as an engineer right now. The engineers just study with the books in his hand, but we, the farmers, live with the soil. So, we know better than the engineer what the soil needs' (E20).

Quite apart from commonly accepted framings of sustainability as contingent on soil or water conditions, these narratives clearly affirm that "environmental politics are always entangled with a cultural politics of knowing" (Braun and Wainwright, 2001: 41), with contestations over what constitutes appropriate knowledge, or farming, at the core.

\title{
Peasant Scientists: Finite Possibilities and Partial Mobilizations
}

\begin{abstract}
'What is needed is to ensure that the irrigation lasts a long time. I don't know how many years the state has assumed for this irrigation system to last, but I expect that it will be fifty years. Then we will see what will happen. There is a lack of infrastructure, such as drainage canals. Also, the slope of the canalets is incorrect in some places, creating places where the water flows over' (E21, Subyan, Irrigation Technician and Farmer)
\end{abstract}

This quotation, by a rural resident employed as an irrigation technician for one of the Irrigation Unions, provides a worthwhile starting point to consider narratives of environmental change more common to rural residents living in the plain. Subyan accepts that irrigated agriculture in the plain may have finite possibilities. Consistent with other assessments already noted, rural residents demonstrate considerable recognition of environmental degradation occurring with irrigation implementation. $A$ strong majority of survey respondents identified issues related to agricultural pests, soil erosion, rising ground water, salinization, and other issues as problems in their village (for instance, over $65 \%$ of respondents identified many of these issues, see Table 1 ). Validating claims made by engineers, farmers also generally recognize environmental 
degradation associated with over-reliance on cotton and heavy irrigation application. For instance, Subyan, the same technician quoted above explained that at first framers applied excessive irrigation water. Noticing their harvest didn't do well, that the fields desertified, and the groundwater table rose, he explained, farmers responded by applying less, and requesting that draining canals be installed. Despite these changes, Subyan notes that the problems persist.

In terms of other convergences between narratives, one muhtar echoed statements made by several state agents, blaming cotton monocropping on farmers' illiteracy. He said 'it is because of the farmers' illiteracy that they only plant cotton since 1997.' In the next breath, however, he added 'it is a problem though because the state lends support when you plant cotton' (E2), thereby relating another cause for heavy reliance on cotton production among farmers-state crop subsidies. At the time of initial research, the state provided both a nine-cent per kilo subsidy for cotton (US dollar terms, in 2001), and also destek (support, subsidy) for cotton-related pesticides, not necessarily available for other crops. In repeated interviews with state agents the issue of state subsidies for cotton was offered unprompted only once, and this was off the record. By contrast, when farmers spoke about environmental changes in the plain, the issue of state subsidies was noted readily. When a DSi (State Hydraulic Works) engineer was asked directly about the subsidy, he noted: 'The subsidy for cotton is a political issue. The government says it does not want people to grow cotton here but still provides the subsidy, they should change this, I'm not sure why they do it' (S7).

In terms of the implications of the subsidy for how farmers convey issues with respect to cotton monocropping, it was mentioned at several points that the predominance of cotton is a result of state support, and without it, some mentioned they would prefer to grow wheat or some other less demanding crop. One farmer complained 'the state only gives us destek_for cotton, so we grow only cotton' (E30). Another explained, 'surely, the subsidy becomes a secondary income for cotton. We don't receive subsidy for any other crop... (also) cotton is better because it is useful to the country's economy' (E20). These and similar statements clearly attribute predominance of cotton not to ignorance of farmers, but to specific state policies (in fact, many demonstrated significant awareness of the difficulties that heavy reliance on cotton poses). ${ }^{12}$ As such, these stories offer different dimensions to assessments of irrigated agriculture in the plain. With respect to cotton pesticide subsidies specifically, one farmer noted: 'We don't have white fly or green worm this year, but nearby villages are struggling with it...the state gives us 30 per cent towards the bill for ilaç (pesticides) associated with cotton...we don't like ilaç if there are not too many pests because it destroys five to ten per cent of the product and decreases the harvest' (E20). Not only are subsidies encouraging cotton production, they are also contributing to use of certain pesticides, with the implicit suggestion that this is how appropriate agriculture is practiced.

\footnotetext{
12 Similar processes have been documented in other contexts, for instance Zimmerer (1996) describes how peasants and herders are blamed for soil erosion in Bolivia, with emphasis on education to address perceived ignorance of farmers. He notes that peasants also adopt these discourses often blaming themselves for the degradation. Similar trends are demonstrated in the GAP region, though the degree to which farmers blamed themselves was less strong than statements related to partial or incomplete state attention to particular issues (e.g. drainage works or land leveling).
} 
With respect to multi-scalar considerations, these types of statements made by farmers clearly connect their local practices (e.g. crop choice or pesticide use) to state practices, as well as to scales and notions of nationalist belonging (e.g. the idea of benefiting the national economy through cotton production). As such, while perhaps counter-intuitive, it is interesting to note themes among narratives offered by rural residents tend to situate changes underway within wider fields of political, economic, and ecological processes, offering challenge to what is meant by 'local knowledges.' By contrast, a number of the portrayals by state agents tended to geographically fix these problems, defining them in terms of particularities of place (e.g. in relation to socio-cultural attributes or soil characteristics of those places). Such tendencies further challenge neat binaries separating local from expert knowledge, particularly confounding common scalar and spatial associations with such knowledges.

Still other issues also came up in interviews with farmers that further illuminate preference for cotton production. For instance, many noted that the irrigation scheduling makes it difficult for farmers to grow something other than the dominant crop, enforcing tendencies towards crop homogenisation. One farmer living in the northern part of the plain complained that worms in the cotton fields have been especially bad this year. I asked, 'what will you grow next year?' He replied, 'of course, cotton, we don't have another choice. A few years ago we tried growing tomatoes, but we couldn't sell it, the tomatoes remained in our hands' (E30). This reveals that even if farmers prefer to grow other crops, marketing constraints in the region provide little opportunity to do so. Again, the broader political-economic context is highlighted rather than only focusing in a technological sense on what crops are possible given soil or climatic conditions-the predominant approach of a state research station in the region that tests suitability of different crops for the local climatic and soil conditions.

Highlighting such issues contributes to an enriched understanding of the complex issues at play with respect to crop choice, water use, changing soil conditions, and other key dimensions of environmental change in the region. The issues that come to light by evaluating diverse narrations of change clearly displace attention from the need to convince farmers to grow other crops (and to explain to farmers why mono-cropping is detrimental, as a number of state agents and independent scientists suggest), to the need to more actively encourage other types of agro-industrial investment or create flexible scheduling arrangements to enable alternative cropping choices. ${ }^{13}$ Juxtaposing these narratives, and highlighting certain points of tension and overlap, also reaffirms other works that have suggested that that categories of local, farmer, or state knowledge are much more elusive and hybridized than we may assume. While it may appear that previous sections have replicated artificial separations between categories of state, expert, or local knowledge, in the next section I consider hybridities and elisions across these categories more fully.

\footnotetext{
13 The current system reinforces tendencies towards monoculture as the delivery schedule is largely determined by needs for cotton production. With this system, it would be very difficult for a small number of farmers to grow something other than predominant crop.
} 


\section{DIVERGENCES AND CONVERGENCES: LEARNING FROM DIFFERENT NATURES}

'How is it that a range ecologist in semiarid southern Africa, drawing upon scientific research....can point to evidence of desiccation, land degradation, and the poor condition of cattle, while a pastoralist denies that the range is degraded...?...Two pairs of people are looking at the same landscape, but drawing upon completely different cultural and professional repertoires to interpret it. They see, or fail to see, different things and interpret their landscapes in a different way: in short, different people, different nature'

Blaikie, 2001: 132)

(Piers

Political ecologists, anthropologists, and development studies scholars have provided many examples where attention to local knowledges offers a much more complex understanding of key developmental and environmental shifts. Indeed, to some, reading the above sections might seem frustratingly familiar-many others have convincingly brought farmers' or herders' knowledge to bear to contest statist narratives of peasant backwardness (e.g. Bassett and Crumley 2003), while others have drawn on historical and ecological data to correct biases inherent in colonial narratives (e.g. Davis, 2005). Resonant with studies of this type, the work here validates that attention to diverse and contested knowledges is crucial to adequately assess contours of environmental and developmental changes. However, my goal in the next two sections is to move beyond this basic lesson. Instead, I ask: what can be gained by more fully considering the complex interplay, and points of convergence and divergence between different narratives of environmental change?

The analysis from Turkey reveals that there are indeed key points of divergence across the narratives of change, only some of which might be anticipated by positionality of the actors. More important, I argue, there are also key convergences and shared elements across the narratives that also require attention. A key point is that while the quote by Blaikie, or other situated knowledges perspectives (cf. Haraway, 1991) appear to suggest an infinite array of possibilities, we need to move beyond acknoweldgement of multiplicity of knowledges, or valorization of local knowledges, to explicitly theorize key divergences and convergences across the narratives. How and why do certain elements hold together across narratives from diverse actors, or why do narratives tend to diverge in some (expected) ways, but not others? It is precisely an analytic that highlights both divergences and convergences among knowledges that distinguishes this effort from other discussions related to incorporating local knowledges into project planning, or from 'ideal type' analyses. Instead, the central question is what attention to the complex mapping of diverse and contested narratives of environmental change offers to sustainability debates, to development planners, or to evaluations of environmental change?

It is clear from a range of sources that degradation is accompanying continued irrigation 
implementation in southeastern Turkey. Complementing scientific assessments of these changes, diverse narratives of change from the region appear to agree on a list of threats to sustainability (e.g. salinization, monocropping). Attention to local narratives also enriches understanding of likely factors that contribute to this degradationhighlighting state subsidies for cotton, the lack of financial or institutional incentives to conserve irrigation water, or incomplete implementation of needed land levelling and drainage installation. However, even agreement with respect to these storylines among many, the causal attributions and emphasis on the relative importance of these factors varies. $^{14}$

In terms of another convergence, the accounts of environmental change from this context share a striking similarity with a number of other accounts of degradation associated with cash cropping, implementation of hybridized seeds, or other similar technologies (e.g. Yapa, 1996). In many other accounts of the green revolution or similar changes, however, recognition of degradation is often taken to question the appropriateness of techno-scientific interventions, with some casting these off as altogether devastating (Escobar, 1995; Shiva, 1993). By contrast, narratives of environmental change in newly irrigated areas of the Harran reveal that farmers and state agents both engage the evidence of environmental degradation to argue for more techno-science,$^{15}$ and more state intervention, rather than less. Villagers repeatedly called for more state involvement (e.g. $59 \%$ of survey respondents said that the Turkish state should own the irrigation water), continuing drainage and land-levelling by state agencies, and many farmers asked for more effective pesticides to battle worms and other pests that were increasing in their fields. This is an example of one intriguing puzzle revealed by the mapping of points of overlap and divergence between different environmental narratives. Why is it that both farmers and state agents witness and recognize degradation and losses associated with irrigated agriculture implementation, yet it is at this same moment that they come to valorize and retrench techno-scientific solutions and approaches?

This valorization invites further elaboration as to why this might be the case, even if only speculative. Unlike other accounts of similar processes, farmers and state agents in this region do not appear to long for a return to traditional livelihoods prior to irrigation. ${ }^{16}$ Further, the evidence of degradation is not taken to question the appropriateness of irrigated agriculture, nor to challenge state practices and development efforts in the region (over $80 \%$ of respondents assess irrigation-related changes as 'very positive' or 'positive', in contrast to less than $10 \%$ of respondents who consider changes to be 'very

\footnotetext{
${ }^{14}$ Dahlberg (2000) makes a similar finding. In his study of degradation in Botswana, he found that the same environmental characteristics were found to produce different explanations of cause and effect among villagers. As such, he argues generally for the utility in including villagers' perspectives in analysing changes.

${ }^{15}$ Recognizing the difficulty of a term such as 'techo-science,' I use it here to refer to the ways that tools, practices, and techniques undertaken in the Harran plain are embedded in larger fields of techno-scientific practices and principles, specifically scientific norms and principles developed from research and study across contexts that serve to underwrite the complex of changes in the southeast: from dam building on the Tigris-Euphrates to irrigation delivery and changing agricultural techniques.

${ }_{16}$ Among rural residents of the Harran plain, a notable exception might be those who previously engaged in animal husbandry and nomadism, as some respondents did talk fondly of food and livelihoods prior to settled irrigated agriculture, and before cotton in particular.
} 
negative' or 'negative'). Instead, farmers in the Harran plain request new and better seeds, more effective pesticides, irrigation training, land levelling, drainage works-all amounting to demands for more state involvement, rather than less. These sorts of community assertions of the need for engagement with modes of modernization and change have been observed elsewhere as well (see Rangan, 1996). In Bebbington's $(1996,1993)$ earlier work from Ecuador, indigenous organizations actively promote the use of green revolution technologies-exposing interesting ambivalences in terms of local development strategies, and notions of appropriate modernization. Together with this case study, such examples invite consideration of how and why different groups might share interest in adoption of certain technologies, or might share imaginaries related to modernization, despite radically different political perspectives and positionalities $?^{17}$ Considered together, a foundational aspect of many narratives from southeastern Turkey is that they appear to maintain faith that the appropriate scientific knowledge is available and only needs to be more effectively conveyed and implemented. In this way, local narratives mirror some foundational elements of the broader assessments of degradation from the scientific literature. While degradation is observed, there is implicit faith that the appropriate technology can, and will, be applied. Thus, a theme common to all narratives is that sustainability remains possible, even if elusive for the moment. For many state agents, it is a matter of teaching appropriate techniques to farmers. For many farmers, it is a question of the state following through on land levelling, drainage works, or other applications that are believed to alleviate the problems. Even among those farmers who actively assert their own farming knowledge against that of the engineers, there is still a degree to which the very idea of appropriate irrigation or sustainability is maintained as possible, and is held beyond question (Subyan's quote about limitations of irrigation potential is perhaps an exception). For instance, a farmer in the southern part of the plain speaks of his ability to wash salts from the soil, insisting that the salinization problem he is experiencing is not from the irrigation, as the water coming from the Euphrates is clean. ${ }^{18}$ For him the problem is from was the water pumped previously from wells. In other words, the farmer believes that the problems are in the past, and now things are improving, and are likely to continue to improve with further irrigation implementation.

It is worth noting that Adams and Watson (2003) draw parallel assessments from their work on irrigation in Kenya. These authors also note that while outside observers often point to soil erosion as part of broader crisis narratives to suggest that irrigation in the Marakwet region of Kenya is unsustainable, farmers of the region demonstrate very little concern in this regard. Worsening erosion is recognized by farmers, viewed as a result of inefficient or poor application of anti-erosion methods, but not taken as evidence that problems associated with erosion or irrigation are insurmountable and should be abandoned writ large. Instead farmers accept soil erosion as part of the dynamic environment in which they live and farm, and give no indication that evidence of

\footnotetext{
17 As Bebbington (1993) suggests, the fact that different groups value green revolution technologies does not mean that all groups have the same conceptions of modernization. Indeed, essential differences remain in terms of selfmanagement, notions of local space, and so forth.

${ }^{18}$ As he notes, 'The soils are already salty, it is not the water. The water coming from the Atatürk dam is clean and it actually washes out the salt. The salinization occurred when we irrigated with well water' (E5).
} 
degradation calls into question their approach to agriculture, or the suitability of irrigation in this context (see also van Dissel and de Graaff example from Burkina Faso, 1998). In both the Turkish and the Kenyan examples, the potential for sustainability appears to remain unquestioned, and the continued implementation of irrigated agriculture is valorized.

These types of convergences between lay-knowledges and state or expert opinion open up the question of situated knowledges beyond the acknowledgement that there are diverse knowledges, dependent on social or physical location or positionality to consider what factors, processes, and relations account for, or enable, differential, and shared, understandings and representations? For farmers in the Harran plain, it is possible to imagine that many have no choice but to remain hopeful about the potential for irrigation to bring improvement to their lives. The relative poverty and underdevelopment in the region, as well as histories of Kurdish and Iraqi conflicts that have plagued the region, bring this possibility into relief (see Author, 2008a, Harris, 2002). Along these lines discourses about the southeast being 'left out' of Turkish state efforts have long been invoked by Kurdish separatists and others, helping to explain why some farmers might particularly welcome further Turkish state intervention in the region. For these sorts of reasons, understanding adverse effects of irrigation changes and even associated risks to their livelihoods or health, may not therefore translate into scepticism and distrust of irrigation or state-led development more generally. Perhaps it simply cannot, because this would also entail uncertainty about future possibilities for their survival and wellbeing. For state agents as well, given that it was Turkish state that implemented delivery of irrigation to the region in the hopes of improving standards of living among these residents, it is perhaps not surprising that preliminary evidence related to the negative effects of irrigation are not taken as referenda on the suitability of irrigated agriculture in the region. Thus, while farmers and state agents appear to focus on divergent obstacles to sustainable irrigated agriculture in the region, neither appears to take the evidence of degradation to mean that one should be pessimistic about irrigated agricultural potential in general.

Related to striking convergences between narratives, as well as ways this reading stands apart from other studies of irrigation-related degradation, it is also notable that at times while talking with residents in southeastern turkey, irrigation and technology seem to be elevated to mythic proportions. Farmers made statements that conveyed a sense that irrigation was a change that was a long-awaited improvement in their lives. As one farmer said, 'when water came to the village, life came as well...but we will have to work hard, then we will be rich, but we will need to work hard' (M3). As mentioned above, and discussed in more detail elsewhere (Author, 2008b), despite many negative effects of irrigation, an overwhelming majority of farmers view on the whole very positively (with over $2 / 3$ of farmers on the survey noting that irrigation has been either 'beneficial', or 'very beneficial'). Clearly, irrigation technology is taken for more than the ability to water fields and grow different crops, but is considered to be a point of entry for other possibilities, perhaps even viewed as an opening for broader associations with modernity or wealth. Indeed, before widespread canalet irrigation in the plain, only those farmers who were already well-off were able to afford pumped irrigation water to grow cotton. As such, irrigation generally, and cotton cropping specifically, remain 
symbolically linked to wealth and prestige in the region. This connects the logic for many living and working in the region that now that irrigation is available to everyone, the wealth and prestige will surely follow (ibid).

Along these lines, it also seems likely that irrigation and associated technology holds symbolism in term of associations with modernity and rapprochement with the West. Specifically, irrigation in this region appears to symbolically transgress divides between the West and non-West, industrialized and non-industrialized, developed and nondeveloped or European and non-European (both within Turkey and more generally). These constellations of difference, and related associations with progress and wealth have long-marked Turkish cultural politics, and the relative under-development of the Kurdish-dominated southeast in particular. Given the centrality of these constructions to the history and geography of Turkey, and the southeast, the potential of these binaries to mark contemporary notions of development and progress cannot be understated. Indeed the frequency with which these types of binaries continue to be invoked in Turkey-EU discussions only adds further to the saliency of these constructions to contextualize environmental narratives. Certain types of degradation may be considered the necessary price on the path to realizing certain lifestyles and systems of production more in line with those of the West (c.f. Appadurai, 1996, see also Author, 2008a for discussion). In this sense, situated knowledges of both state agents and farmers are distinct, but also similar to the extent that they share identification and investment in transcending notions of West-non-West or other divides that have been so central to the histories and geographies of the region, and to Turkey more generally.

\section{CONCLUSION: ENVIRONMENTAL CALCABILITIES/ ASSESSING SUSTAINABILITIES}

In many studies of sustainability, the environment itself is taken as the central object of analysis, with scientists endeavouring to measure and assess its features, or calculate rates or implications of change. Here, I have taken up on Cronon's (1992) suggestion that we need not only to tell stories about nature, but also to tell stories about stories about nature. In so doing, this article adds to a body of work that forcibly suggests that the rates of salinization or measurements of soil runoff hold little relevance for sustainability debates without a sense of how those changing agro-ecological conditions are understood, interpreted, negotiated, and conveyed by farmers, extension agents, irrigation engineers, or others living and working in affected regions. As I have argued, mitigation, adaptation, and long-term sustainability of irrigation in the Southeastern Anatolian region are dependent on the meanings attached to ongoing changes at least as much, if not more so, than it is on the soil and water characteristics of the region (cf. Veihe 2000, Warren, 2002, Sayre, 2004).

Building on political ecological works that have brought attention to the complexities of 
why certain environmental changes occur, what challenges such pose to individuals, or what potential we might have to alter practices, this article has argued specifically for the need to engage further in assessments of local narratives of change. I have attempted to move beyond studies that seek to engage local narratives with the goal of correcting value-laden or prejudicial narratives (as with works that challenge colonial or Malthusian narratives, for instance), that focus on abstracted or 'national' policy narratives, or that analyze narratives based on 'ideal types' or positionality. Specifically, the work here addresses the gulf, and related weaknesses, that persists between interest in local knowledges, and narrative and discursive approaches to date.

Seeking to bridge elements of these approaches, I argue for an analytic that explicitly theorizes key convergences and divergences between contested narratives of change. This allows us to move beyond enriched understanding of changes through a more complex picture of political economy or cultural politics related to socio-natures, to also consider how and why certain elements of narratives may be shared across diverse actors in particular contexts. As the Turkish case has shown, we can only begin to appreciate the shared faith in technoscience, and the shared interest among actors in state involvement, when we evaluate the mapping of narratives in relation to broader power dynamics, histories, and contextual issues specific to contemporary Turkey-EU debates, or histories of the Southeastern Anatolia region. My argument is, in part, that the positive valences related to irrigation technology that appear to be shared by most actors living and working in the region are likely to be very significant in conditioning mitigation strategies and other future agroecological possibilities in the region.

Focus on the divergences and convergences of environmental narratives also helps to avoid problems of treating knowledges as homogenized, stable, or isolateable (ideals of 'local' or 'state knowledges'), furthering arguments of other scholars who have tried to encourage us to think about the complexity of knowledges. The example of southeastern Turkey also goes beyond the claim that farmers' understandings of environments may differ from technical assessments, or that farmers may selectively enrol certain scientific explanations as part of hybridized knowledges. Instead, the example highlights some of the complex layers of meaning, and politics related to narratives of change. In particular, changing agro-ecologies in Turkey's southeast cannot be abstracted from histories of difference West-Non-West, European-nonEuropean and industrialized, non-industrialized divides and the uneven relations of power implicit in each.

By considering the stories that we tell about environments, we can also think seriously about what narratives implicitly authorize, particularly when aspects of story lines are broadly shared. In this case, narratives converge in way that implicitly authorizes further state involvement and irrigation implementation. Additionally, there are key convergences in that actors generally do not take evidence of degradation to question the appropriateness of irrigated agriculture for this region, or to suggest that sustainability of irrigated agriculture is not possible. Instead, actors repeatedly call for new and better seeds, new and better irrigation technologies, and other approaches that they believe will bring sustainability to the region. This case adds force to calls to focus more precisely on the portrayals of environments themselves as objects of analysis, and what sort of insights analysis of this type might afford (c.f. Nightingale, 2003). It is only 
by recognizing the degree of overlap of narratives around the suitability of irrigation for this region, and the faith in sustainability in a general sense, that we can begin to understand the shared commitment to particular agroecological futures in this region.

Returning to the story of Yaytaş that was featured at the beginning of this article, even with many examples of studies that have highlighted the importance of local knowledge, there is clearly still a need to deal more adequately with complexities and interpays of 'local knowledges' in assessments of environmental change. Context specificities matter not only in terms of local soil characteristics, or ground-truthing locations of canalets, but there is also a need to be attentive to the complex mappings of environmental narratives as they circulate among and are invoked by diverse agentshow might certain storylines, plots, and meanings by enrolled by different actors to describe changes they experience, and to what effects? With more attention to divergent and convergent knowledges, and the interlinked cultural politics of knowing implicit in these mappings, studies of environmental change and sustainability can move beyond discussions of whether a system is sustainable, or even beyond Sneddon's redefinition of the questions as 'what is being sustained, for whom, and by what mechanisms?' Instead, we can investigate key issues related to how notions of sustainability or unsustainability are variously enrolled, articulated, and reproduced. In the case from southeastern Turkey, the faith in sustainability that is upheld by these diverse narratives is a significant finding, and needs to be unpacked. What work does the implicit invocation of sustainability of irrigation systems do in terms of enabling or limiting particular agricultural practices, state practices, or even scientific endeavors? Proctor (2001: 229) provides warning with respect to the need to more fully situate our knowledges of environments with respect to the particularities of context and also in relation to socio-political dimensions of knowledge production. As he writes, "alarming biophysical facts and seemingly self-evident values concerning nature do not stand outside of a social context, and that context itself must be interrogated, even in what appears to be an incontrovertible case..." Analysis of multi-scalar, embedded, and interlinked narratives of environmental change and (un)sustainabilities offer compelling ways forward in this regard.

\section{ACKNOWLEDGEMENTS:}

Research sponsors include Jacob K. Javits program of the U.S. Department of Education, MacArthur Program on Global Change, Sustainability, and Justice of the University of Minnesota, the American Research Institute in Turkey, and the Department of Geography and the Graduate school at the University of Wisconsin-Madison. Special thanks also to Nurcan Atalan-Helicke for research assistance. 


\section{BIBLIOGRAPHY}

Adaman, F. and G. Özertan, 2007. Perceptions and practices of farmers towards the salinity problem: the case of Harran Plain, Turkey. International Journal of Agricultural Resources, Governance and Ecology, 6(4/5): 533 - 551.

Adams, W. M. and E. E. Watson, 2003. Soil Erosion, Indigenous Irrigation and Environmental Sustainability, Marakwet, Kenya. Land Degradation and Development, 14: 109 - 122.

Adger, N. W., T. Benjaminsen, et al., 2001. Advancing a Political Ecology of Global Environmental Discourses Development and Change, 32: 681 - 715.

Agrawal, A., 1995. Dismantling the divide between indigenous and scientific knowlege. Development and Change, 26: 413 - 439.

Akbaba, I. G., 2001. GAP with its light and shadow Bilim ve Teknik, 401.

Appadurai, A., 1996. Modernity at Large: Cultural Dimensions of Globalization. Minneapolis, MN: University of Minnesota Press.

Author, 2008a. Modernizing the Nation: Postcolonialism, (Post)Development, and Ambivalent Spaces of Difference in Southeastern Turkey Geoforum, 39: 16981708.Author, 2008b. Water Rich, Resource Poor: Intersections of Gender, Poverty and Vulnerability in Newly Irrigated Areas of Southeastern Turkey World Development, 36(12): 2643-2662.

Bakker, K. and G. Bridge, 2006. Material worlds? Resource geographies and the 'matter of nature'. Progress in Human Geography, 30(1): 5 - 27.

Bassett, T. and D. Crummey, 2003. African Savannas: Global Narratives and Local Knowledges of Environmental Change. Portsmouth, $\mathrm{NH}$ : Heinemann.

Bebbington, A., 1996. Movements, Modernizations, and Markets: Indigenous organizations and agrarian strategies in Ecuador In Peet, R. and M. Watts, eds. Liberation EcologiesLondon: Routlege, pp.86-109..

Bebbington, A., 1993. Modernization from Below: An Alternative Indigenous Development? Economic Geography, 69(3): 274 - 292.

Berkes, F. M. K., C. Folke, M. Gadgil, 1998. Exploring the Basic Ecological Unit: Ecosystem-like Concepts in Traditional Societies Ecosystems 1: 409-415.

Birkenholtz, T., 2008. Contesting Expertise: the politics of environmental knowledge in northern Indian groundwater practices. Geoforum, 39: 466 - 482.

Blaikie, P., 2001 Social Nature and Environmental Policy in the South: Views from Verandah and Veld Inin N. Castree and B. Braun, eds. Social Nature . London: Blackwell, pp. 133-150.

Braun, B. and J. Wainwright, 2001. Nature, Poststructuralism, and Politics In N. Castree and B. Braun, eds. Social Nature London: Blackwell, pp. 41-63. 
Briggs, J. and J. Sharp, 2004. Indigenous Knowledges and development: a postcolonial caution. Third World Quarterly, 25(4): 661 - 676.

Brosius, P., 2006. What counts as local knowledge in global environmental assessments and conventions? In W. Reid, F. Berkes, D. Capistrano and T. Wilbanks, eds. Bridging Scales and Knowledge Systems: Concepts and Applications in Ecosystem Assessment. Washington DC: Island Press, pp.129-144.

Cowell, R. and H. Thomas, 2002. Managing Nature and Narratives of Disposession: Reclaiming Territory in Cardiff Bay. Urban Studies, 39(7): 1241 - 1260.

Cronon, W., 1992. A place for stories The Journal of American History, 78 (4):13471376.

Çullu, M. A., A. Almaca, Y. Şahin, S. Aydemir, 2002. Application of GIS for Monitoring Salinization in the Harran Plain, Turkey. International Conference on Sustainable Land Use and Management, pp 326-331.

Dahlberg, A. C., 2000. Interpretations of Environmental Change and Diversity: a critical approach to indications of degradation-the case of Kalakamate, Northeast Botswana. Land Degradation and Development, 11: 549-562.

Davis, D., 2005. Indigenous Knowledge and the desertification debate: problematising expert knowledge in North Africa, Geoforum 36: 509 - 524.

Escobar, A., 1995. Encountering Development: The Making and Unmaking of the Third World. Princeton: Princeton University Press.

Gregory, D., 2001. (Post) Colonialism and the Production of Nature In N. Castree and B. Braun, eds. Social Nature London: Blackwell, pp. 84-111.

Gupta, A., 1998. Postcolonial Developments: Agriculture in the Making of Modern India Durham: Duke University Press.

Hajer, M. A,. 1995. The Politics of Environmental Discourse: Ecological Modernization and the Policy Process. Oxford: Clarendon Press.

Haraway, D., 1991. Situated Knowledges: The Science Question in Feminism and the Privilege of Partial Perspective In Simians, Cyborgs, and Women: The Reinvention of Nature. New York: Routledge, pp. 183-201..

Johnson, J. R. Pualani Louis, A. Pramono, 2006. Facing the Future: Encouraging Critical Cartographic Literacies in Indigenous Communities. ACME International Journal of Critical Geographies, (4) 1: 80-98.

Kloppenburg, J., 1991. Social theory and the de-reconstruction of agricultural science: local knowledge for an alternative agriculture Rural Sociology, 56 (4): 519-548.

Krogh, L., 1997. Indigenous soil knowledge among the Fulani of northern Burkina Faso: linking soil sicence and anthropology in analysis of natural resources management. Geojournal, 43: 189 - 197.

Lee, H. F. and D. D. Zhang, 2004. Perceiving desertification from the Lay perspective in 
Northern China. Land Degradation \& Development, 15: 529 -542.

Lélé, S., 1991 Sustainable Development: A Critical Review World Development, 19(6): 607-621.

Murdoch, J. and J. Clark, 1994. Sustainable Knowledge. Geoforum, 25(2): 115 - 132.

Nightingale, A, 2009a. Triangulation In N. Thrift, R. Kitchin, eds. International Encyclopedia of Human Geography

Nightingale, A, 2009b. Oral History: Oral Ecological History In N. Thrift, R. Kitchin International Encyclopedia of Human Geography

Nightingale, A., 2003. A Feminist in the Forest: Situated Knowledges and Mixing Methods in Natural Resource Management Acme: an international e-journal for critical geographies, 2(1): 77-90.

Nygren, A., 1999. Local Knowledge in the Environment-Development Discourse. Critique of Anthropology, 19(3): 267 - 288.

Ostrom, E., 1990. Governing the Commons: The Evolution of Institutions for Collective Action. Cambridge: Cambridge University Press.

Ozdoğan, M. 2006. Changes in Summer Irrigated Crop Area and Water Use in Southeastern Turkey 1993 to 2002: Implications for Current Use and Future Water resources Water Resources Management, 20: 467 - 488.

Paulson, S. and L. Gezon, 2005. Political Ecology across spaces, scales and social groups New Brunswick, NJ: Rutgers University Press.

Peet, R. and M. Watts, 1993. Introduction: Development Theory and Environment in the Age of Market Triumphalism Economic Geography, 69(3): 227-253.

Peet, R. and M. Watts, 1996. Liberation Ecologies: Environment, Development and Social Movements. London: Routledge.

Postel, S., 1999. Pillar of Sand: Can the Irrigation Miracle Last? New York and London: W. W. Norton \& Company.

Proctor, J., 2001. Solid Rock and Shifting Sands: The moral paradox of saving a socially constructed nature In N. Castree and B. Braun, eds. Social Nature. London: Blackwell, pp. 225-240..

Rangan, H., 1996. From Chipko to Uttaranchal: Development, environment, and social protest in the Garhwal Himalayas, India In R. Peet and M. Watts, eds. Liberation Ecologies. London: Routledge, pp. $205-226$.

Sayre, N., 2004. Viewpoint: the need for qualitative research to understand range management. Journal of Range Management, 57: 668 - 674.

Scott, J., 1998. Seeing Like a State. New Haven: Yale University Press.

Shiva, V., 1993. The Violence of the Green Revolution: Third World Agriculture, Ecology and Politics. Penang: Third World Network. 
Sneddon, C., L. Harris, R. Dimitrov, and U. Özesmi, 2002.. Contested Waters: Social Conflict, Spatial Scale and Sustainability in Aquatic Systems Society and Natural Resources, 15: 663-675.

Sneddon, C, 2000. 'Sustainability' in ecological economics, ecology and livelihoods: a review Progress in Human Geography, 24(4): 521-549.

Şelli, F. and A. Koral, 2000. Adaptation of New Technologies and Socio-Economic Changes in the Agricultural Plains of Sanliurfa Harran Plain After Irrigation and Possible Problems. Sanliurfa: Village Services General Management Research Institute Publication.

Tsing, A., 2005, Friction: An ethnography of global connection Princeton, NJ: Princeton University Press.

Turner, M., 1999. No Space for Participation: Pastoralist Narratives and the Etiology of Park-Herder Conflict in Southwestern Niger. Land Degradation and Development, 10(4): 345 - 363.

Unver, I. H. O., 1997a. Southeastern Anatolia Project (GAP). Water Resources Development, 13(4): 453-483.

Unver, I. H. O., 1997b. Southeastern Anatolia Integrated Development Project (GAP), Turkey: An Overview of Issues of Sustainability. Water Resources Development ,13(2): 187-207.

Van Dissel, S. C. and J. de Graaff, 1998. Differences between farmers and scientists in the perception of soil erosion: a South African case study Indigenous Knowledge and Development Monitor, 6(3): 8 - 9.

Veihe, A., 2000, Sustainable Farming Practices: Ghanian Farmers' perception of erosion and their use of Conservation Measures Environmental Management, 25 (40): 393-402.

Visser, S. M., J. K. Leenders, and M. Leeuwis, 2003. Farmers' Perceptions of Erosion by Wind and Water in Northern Burkina Faso Land Degradation and Development, 14:123 - 132.

Yapa, L., 1996. Improved Seeds and Constructed Scarcity InR. Peet and M. Watts, eds. Liberation Ecologies London: Routledge, pp. 69-85.

Zimmerer, K. S., 1996. Discourses on Soil Loss in Bolivia: Sustainability and the search for socioenvironmental 'middle ground' In R. Peet and M. Watts, eds. Liberation Ecologies. London: Routledge, pp. 110-124. 